\title{
Synthesis and antibacterial activity of novel lincomycin derivatives. I. Enhancement of antibacterial activities by introduction of substituted azetidines
}

\author{
Ko Kumura, Yoshinari Wakiyama, Kazutaka Ueda, Eijiro Umemura, Takashi Watanabe, Eiki Shitara, \\ Hideki Fushimi, Takuji Yoshida and Keiichi Ajito
}

The synthesis and antibacterial activity of (7S)-7-sulfur-azetidin-3-yl lincomycin derivatives are described. Modification was achieved by a simple reaction of (7R)-7-O-methanesulfonyllincomycin and the corresponding substituted azetidine-2-thiol. Several compounds first showed moderate antibacterial activity against Streptococcus pneumoniae and Streptococcus pyogenes with erm gene as lincomycin derivatives.

The Journal of Antibiotics (2016) 69, 440-445; doi:10.1038/ja.2015.134; published online 13 January 2016

\section{INTRODUCTION}

Lincosamide antibiotics are prokaryotic translation inhibitors that act on the $50 \mathrm{~S}$ ribosome in a similar manner to macrolide antibiotics. Clindamycin (CLDM) derived from lincomycin (LCM) is a useful semisynthetic antibiotic (Figure 1) that is effective against staphylococcal and streptococcal infections. However, those lincosamides show almost no antibacterial activity against resistant pathogens such as Streptococcus pneumoniae and Streptococcus pyogenes with erm gene. Erm methyltransferases methylate A2058Ec of rRNA and diminish the affinity of clinically important macrolides, lincosamides and streptogramin B. ${ }^{1}$ Emergence of resistant bacteria is a serious concern in clinical sites. ${ }^{2}$ The crystal structures of bacterial $23 \mathrm{~S}$ ribosomal rRNA complexed with CLDM showed several hydrogen bonds between a sugar moiety of CLDM and the peptidyl transferase cavity composed of such as A2058Ec, G2520Ec and A2059Ec. ${ }^{3}$ This finding explains the reason why chemical modifications of the sugar moiety of lincosamide result in drastic loss of antibacterial activity. ${ }^{4}$ On the other hand, there is a hydrophobic space around the C-7 position of CLDM in the crystal structure and it is consistent with the fact that modifications at the C-7 position of LCM tend to give comparable antibacterial activity to that of LCM. ${ }^{5,6}$ Sztaricskai et al. ${ }^{5}$ reported compounds $\mathbf{1}$ and 2, which have a heteroaryl group via sulfur atom with $(7 R)$ configuration. We supposed that $(7 S)$ configuration is more suitable for target interaction from reported structure-activity relationships $(\mathrm{SAR})^{6}$ and the three-dimensional structural information. So far, we synthesized many (7S)-7-sulfur-substituted LCM analogues, ${ }^{7}$ and we describe the first-generation derivatives among them in this report. Thus, we intended to incorporate an azetidine ring instead of the aromatic heterocycle. The azetidine ring is sometimes used in antibiotics chemistry, for example, $\beta$-lactam antiinfective, new quinolone and aminoglycoside: tebipenem, ${ }^{8}$ delafloxacin ${ }^{9}$ and a tobramycin derivative $^{10}$ (Figure 2). Although some of these compounds have different mode of actions from lincosamide, we attempted to incorporate the azetidine ring to lincosamide at the C-7 position via sulfur atom with $(7 R)$ configuration to generate novel lincomycin antibiotics that are active against $S$. pneumoniae and $S$. pyogenes with erm gene.

\section{Chemistry}

Although synthesis of lincosamide derivatives that have a sulfide group at the C-7 position with $(7 R)$ configuration was reported by a simple $\mathrm{S}_{\mathrm{N}} 2$ reaction using CLDM, ${ }^{5,11}$ preparation of lincosamide derivatives that have a sulfide group with $(7 S)$ configuration is limited because a starting material is a natural compound with a single stereochemistry at the C-7. Bannister ${ }^{12}$ reported introduction of an alkyl thiol to the C-7 position with $(7 S)$ configuration utilizing epimine prepared form LCM. This method is unique but requires many steps, and a source of sulfide is limited to dithioacetals or monothioacetals. To establish practical synthetic route, we utilized 2,3,4-tris-O-(trimethylsilyl)lincomycin (5), ${ }^{13}$ which was prepared in two steps from LCM as shown in Scheme 1. After methanesulfonylation of the 7-OH of LCM, nucleophilic substitution of $\mathbf{6}$ with 4 afforded 7 in $48 \%$ yield. Removal of trimethylsilyl groups followed by the deprotection of the amine afforded 8 in $73 \%$ yield. For the synthesis of $N$-substituted derivatives, $\mathbf{8}$ was converted to $\mathbf{9}$ by reprotecting hydroxyl groups of $\mathbf{8}$. N-Aryl analogues 10a, 10b and $10 \mathrm{~d}$ were prepared by an $S_{N} A r$ reaction between 9 and aryl fluoride or chloride. $N$-Alkyl analogues (11a-c) were synthesized via addition of $\mathbf{9}$ to acrylic acid derivatives and reaction of 9 with corresponding acid chloride furnished urea derivatives and amides (12a-e). 
Compound 10e that has the side chain of tebipenem was prepared from 6 with 3-(4,5-dihydrothiazol-2-yl)azetidine-1-thiol ${ }^{8}$ in a similar manner as shown in Scheme 2.

\section{RESULTS AND DISCUSSION}

The antibacterial activities of novel lincomycin derivatives against S. pneumoniae, S. pyogenes and Haemophilus influenzae are summarized in Table 1. CLDM showed potent activity against susceptible pathogens, but MICs against the resistant strains were larger than $128 \mu \mathrm{g} \mathrm{ml}^{-1}$. Compound $\mathbf{8}$ exhibited comparable antibacterial activities to LCM against susceptible Gram-positive strains. Although the antibacterial activities of $\mathbf{8}$ against resistant bacteria were not detected, the result prompted us to explore the SAR of (7S)-7-sulfur-azetidin-3-yl-LCM derivatives. As for the compounds $10 a-d$ that have an aryl group directly to azetidine, all the compounds except 10c showed more potent antibacterial activities against susceptible Gram-positive strains and resistant strains with mef gene than CLDM. It is notable that $10 \mathrm{~b}, 10 \mathrm{~d}$ and $10 \mathrm{e}$ slightly exhibit antibacterial activity against resistant strains with erm gene. As for $N$-alkyl derivatives (11a-c), antibacterial activities were weak and almost the same as those of $N$-unsubstituted compound $\mathbf{8}$, and their weak activities were probably due to their high hydrophilicity. On the other hand, amides 12d and 12e derived from acid chlorides showed similar antibacterial profile to $10 \mathrm{~b}, 10 \mathrm{~d}$ and $10 \mathrm{e}$. Furthermore, urea derivatives $\mathbf{1 2 b}$ and $12 \mathrm{c}$ showed stronger activities against resistant $S$. pneumoniae and $S$. pyogenes with erm gene than $10 \mathrm{~b}, 10 \mathrm{~d}$ and $10 \mathrm{e}$. The antibacterial activities of $\mathbf{1 2} \mathbf{b}$ against susceptible Gram-positive strains are the strongest in this series, and $12 \mathrm{c}$ showed stronger antibacterial activities against $H$. influenzae than CLDM.

\section{CONCLUSIONS}

To generate novel lincomycin derivatives, which are effective against resistant $S$. pneumoniae and $S$. pyogenes with erm gene, we synthesized a series of (7S)-7-sulfur-azetidin-3-yl-LCM derivatives by utilizing the simple substitution reaction. $\mathrm{N}$-Unsubstituted compound $\mathbf{8}$ showed comparable antibacterial activities to LCM against susceptible Grampositive strains. $N$-Aryl, amide and urea derivatives showed weak antibacterial activities against $S$. pneumoniae and $S$. pyogenes with erm gene. Especially, urea derivatives $\mathbf{1 2 b}$ and $\mathbf{1 2 c}$ first exhibited moderate
Lincomycin (LCM): $\mathrm{R}=-\mathrm{OH}$ Clindamycin (CLDM): $\mathrm{R}=\cdots \cdot \mathrm{Cl}$

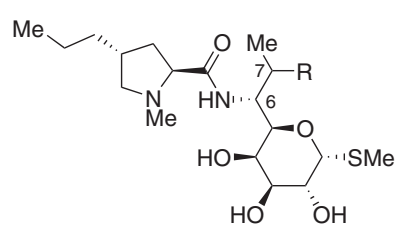

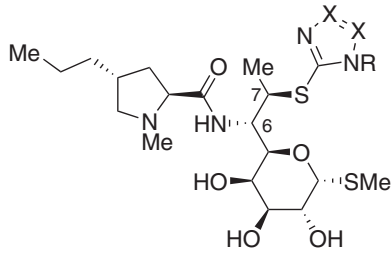

1: $\mathrm{R}=\mathrm{H} ; \mathrm{X}=\mathrm{CH}$ antibacterial activity against those resistant strains as lincomycin derivatives. Thus, we confirmed that the (7S)-7-sulfur-azetidin-3-ylLCM analogue was an attractive framework against the target pathogens.

\section{EXPERIMENTAL PROCEDURE}

\section{General}

${ }^{1} \mathrm{H}$ NMR spectra were measured with a JEOL JNM-GSX 400 (Tokyo, Japan, $400 \mathrm{MHz}$ ) spectrometer in $\mathrm{CDCl}_{3}$ or $\mathrm{CD}_{3} \mathrm{OD}$ with $0.03 \%$ tetramethylsilane as an internal standard. Mass spectra were obtained on a JEOL JMS-FABmate spectrometer or JEOL JMS-700 mass spectrometer or Agilent Technologies 6530-Q-TOF LC/MS mass spectrometer (Agilent Technologies, Santa Clara, CA, USA). The optical rotations were recorded with Jasco P-2300 digital polarimeter (Jasco, Tokyo, Japan). Column chromatography was performed with silica gel (Kanto Chemical, Tokyo, Japan: 60N; spherical, neutral).

\section{tert-Butyl 3-mercaptoazetidine-1-carboxylate (4)}

To a solution of $3(2.48 \mathrm{~g})$ in tetrahydrofuran $(35 \mathrm{ml})$ were added triphenylphosphine $(5.64 \mathrm{~g})$, diethyl azodicarboxylate $(3.92 \mathrm{ml})$ and the mixture was stirred at room temperature for $20 \mathrm{~min}$. To the mixture was added thiobenzoic acid $(2.53 \mathrm{ml})$ and the mixture was stirred at room temperature for $1 \mathrm{~h}$. The mixture was concentrated in vacuo and the residue was purified by silica gel column chromatography (hexane-AcOEt) to give a colorless amorphous $(6.0 \mathrm{~g})$. To a stirred solution of the compound obtained above $(6.0 \mathrm{~g})$ in $\mathrm{MeOH}(50 \mathrm{ml})$ was added $\mathrm{NaOMe}(772 \mathrm{mg})$ and the reaction mixture was stirred for $1 \mathrm{~h}$. Saturated aqueous $\mathrm{NaHCO}_{3}$ was added to the mixture and extracted with AcOEt and the organic phase was dried over $\mathrm{Na}_{2} \mathrm{SO}_{4}$, filtered and concentrated in vacuo. The residue was purified by silica gel column chromatography (hexane-AcOEt) to afford $4(1.81 \mathrm{~g}, 67 \%)$ as a colorless solid. ${ }^{1} \mathrm{H}$ NMR $\left(400 \mathrm{MHz}, \mathrm{CDCl}_{3}\right) \delta 4.32-4.37(\mathrm{~m}, 2 \mathrm{H}), 3.77-3.82(\mathrm{~m}, 2 \mathrm{H})$, 3.61-3.71 (m, 1H), $2.00(\mathrm{~d}, J=8.5 \mathrm{~Hz}, 1 \mathrm{H}), 1.39-1.50(\mathrm{~m}, 9 \mathrm{H})$.

\section{7-O-Methanesulfonyl-2,3,4-tris-O-(trimethylsilyl)lincomycin (6)}

To a cold $\left(0{ }^{\circ} \mathrm{C}\right)$ solution of $5(4.0 \mathrm{~g})$ in $\mathrm{CHCl}_{3}(20 \mathrm{ml})$ were added triethylamine $(2.45 \mathrm{ml})$ and methanesulfonyl chloride $(990 \mu \mathrm{l})$ and the mixture was stirred at room temperature for $3 \mathrm{~h}$. The mixture was diluted with $\mathrm{CHCl}_{3}$ and washed with $10 \%$ aqueous $\mathrm{NaHCO}_{3}$. The organic phase was dried over $\mathrm{Na}_{2} \mathrm{SO}_{4}$, filtered and concentrated in vacuo. The residue was purified by silica gel column chromatography (hexane-AcOEt) to afford $6(4.2 \mathrm{~g}, 93 \%)$ as a colorless solid. ${ }^{1} \mathrm{H}$ NMR $\left(400 \mathrm{MHz}, \mathrm{CDCl}_{3}\right) \delta 7.60(\mathrm{~d}, J=11.0 \mathrm{~Hz}, 1 \mathrm{H})$, $5.16(\mathrm{~d}, J=5.6 \mathrm{~Hz}, 1 \mathrm{H}), 5.10-5.15(\mathrm{~m}, 1 \mathrm{H}), 4.75(\mathrm{dt}, J=3.3,10.3 \mathrm{~Hz}, 1 \mathrm{H})$, $4.15(\mathrm{dd}, J=5.6,9.5 \mathrm{~Hz}, 1 \mathrm{H}), 3.90(\mathrm{~d}, J=9.7 \mathrm{~Hz}, 1 \mathrm{H}), 3.76(\mathrm{~d}, J=2.3 \mathrm{~Hz}, 1 \mathrm{H})$, $3.52(\mathrm{dd}, J=2.3,9.4 \mathrm{~Hz}, 1 \mathrm{H}), 3.15-3.20(\mathrm{~m}, 1 \mathrm{H}), 3.09(\mathrm{~s}, 3 \mathrm{H}), 2.99(\mathrm{dd}, J=3.7$, $10.2 \mathrm{~Hz}, 1 \mathrm{H}), 2.40(\mathrm{~s}, 3 \mathrm{H}), 2.11(\mathrm{~s}, 3 \mathrm{H}), 1.92-2.09(\mathrm{~m}, 3 \mathrm{H}), 1.79-1.89(\mathrm{~m}, 1 \mathrm{H})$, $1.40(\mathrm{~d}, J=6.8 \mathrm{~Hz}, 3 \mathrm{H}), 1.23-1.35(\mathrm{~m}, 4 \mathrm{H}), 0.89(\mathrm{t}, J=6.7 \mathrm{~Hz}, 3 \mathrm{H})$, $0.17(\mathrm{~s}, 9 \mathrm{H}), 0.14(\mathrm{~s}, 9 \mathrm{H}), 0.13(\mathrm{~s}, 9 \mathrm{H})$; MS (ESI) $\mathrm{m} / z 701(\mathrm{M}+\mathrm{H})^{+}$.

\section{7(S)-7-Deoxy-7-[1-(tert-butoxycarbonyl)azetidin-3-ylthio]-2,3,4-} tris-O-(trimethylsilyl)lincomycin (7)

To a solution of $6(10.5 \mathrm{~g})$ and $\mathrm{K}_{2} \mathrm{CO}_{3}(4.15 \mathrm{~g})$ in $\mathrm{N}$, $N$-dimethylformamide $(50 \mathrm{ml})$ was added $4(1.9 \mathrm{~g})$ and the mixture was stirred at $80^{\circ} \mathrm{C}$ for $15 \mathrm{~h}$. After cooled to room temperature, the mixture was diluted with AcOEt and washed with brine. The organic phase was dried over $\mathrm{Na}_{2} \mathrm{SO}_{4}$, filtered and concentrated in vacuo. The residue was purified by silica gel column chromatography

Figure 1 Structures of lincosamides.

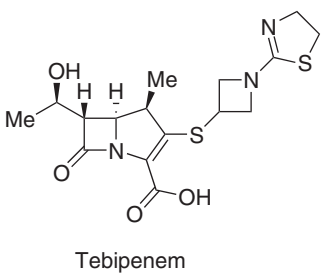

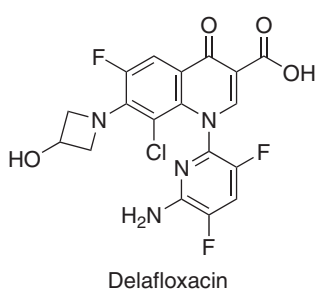

Delafloxacin

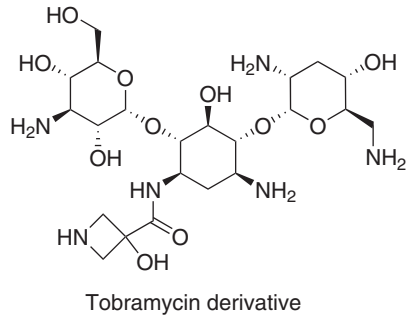

Figure 2 Structures of antibiotics that have an azetidine ring. 


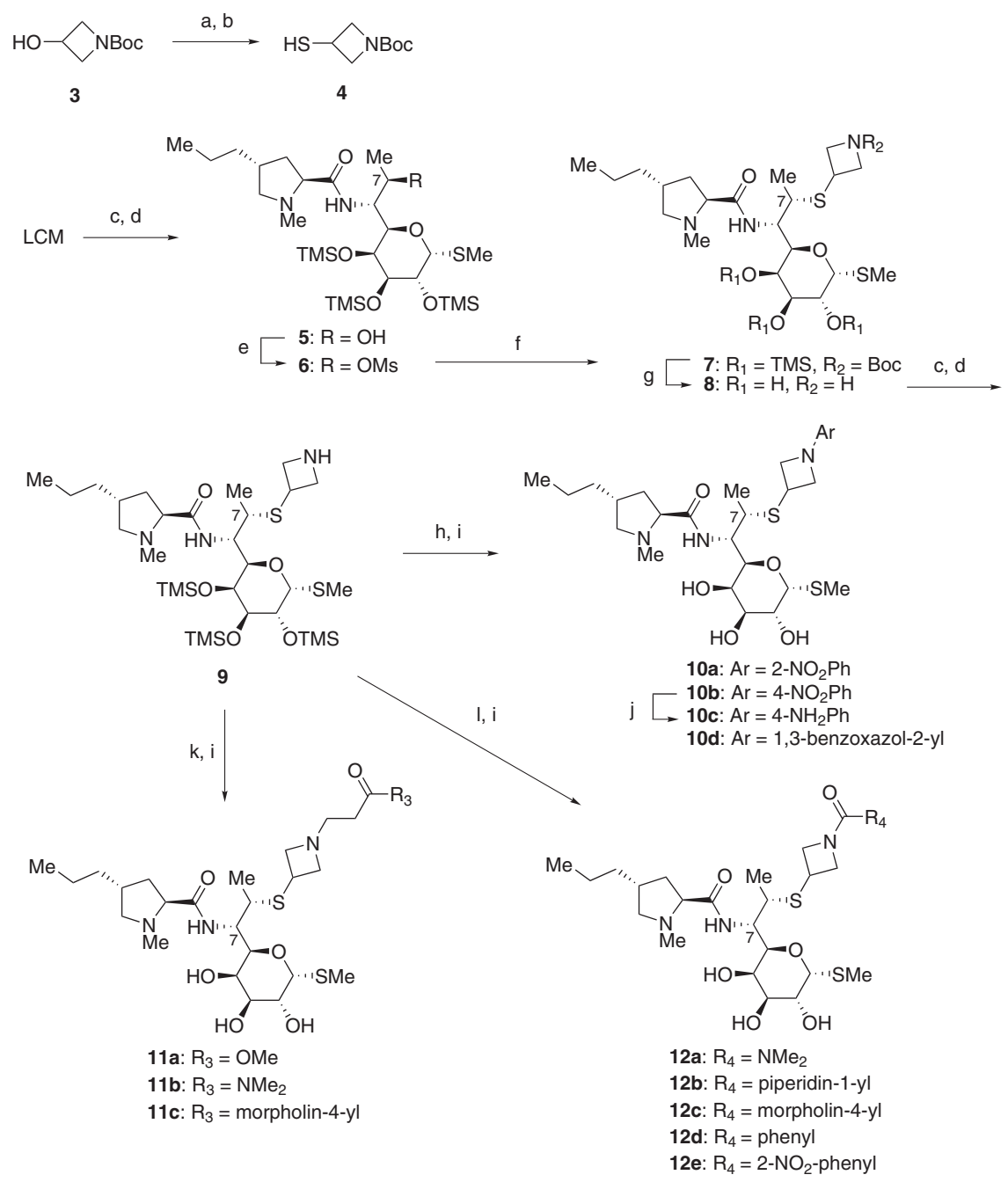

Scheme 1 Synthesis of 7(S)-sulfur-substituted lincomycin derivatives. Reagents: (a) thiobenzoic acid, DEAD, PPh 3 , THF; (b) NaOMe MeOH; (c) TMSCl, HMDS, pyridine; (d) $6 \mathrm{~N} \mathrm{AcOH}, \mathrm{MeOH}$; (e) $\mathrm{MsCl}, \mathrm{TEA}, \mathrm{CHCl}_{3}$; (f) 4, $\mathrm{K}_{2} \mathrm{CO}_{3}$, DMF; (g) $1 \mathrm{~N} \mathrm{HCl}, \mathrm{MeOH}$ then trifluoroacetic acid; (h) XAr, TEA, DMF; (i) $1 \mathrm{~N}$ $\mathrm{HCl}, \mathrm{MeOH}$; (j) $\mathrm{H}_{2}, \mathrm{Pd} / \mathrm{C}, \mathrm{MeOH}$; (k) $\mathrm{CH}_{2} \mathrm{CHCOR}_{3}$, EtOH; (I) $\mathrm{R}_{4} \mathrm{COCl}, \mathrm{DMAP}, \mathrm{TEA}, \mathrm{CHCl}_{3}$.

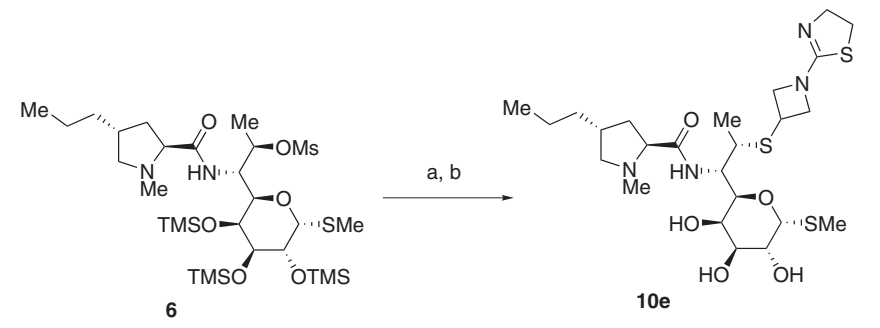

Scheme 2 Synthesis of 10e. Reagents: (a) 3-(4,5-dihydrothiazol-2-yl) azetidine-1-thiol hydrochloride, $\mathrm{K}_{2} \mathrm{CO}_{3}$, DMF; (b) $1 \mathrm{~N} \mathrm{HCl} / \mathrm{AcOEt}, \mathrm{MeOH}$.

(hexane-AcOEt) to afford $7(5.7 \mathrm{~g}, 48 \%)$ as a colorless solid. $[\alpha]_{\mathrm{D}}{ }^{30}+76^{\circ}$ (c 0.46, $\left.\mathrm{CHCl}_{3}\right) ;{ }^{1} \mathrm{H}$ NMR $\left(400 \mathrm{MHz}, \mathrm{CDCl}_{3}\right) \delta 7.47(\mathrm{~d}, J=10.7 \mathrm{~Hz}, 1 \mathrm{H}), 5.21$ (d, $J=5.6 \mathrm{~Hz}, 1 \mathrm{H}), 4.50(\mathrm{dt}, J=1.7,10.3 \mathrm{~Hz}, 1 \mathrm{H}), 4.29-4.16(\mathrm{~m}, 2 \mathrm{H}), 4.15$ (dd, $J=5.6,9.5 \mathrm{~Hz}, 1 \mathrm{H}), 3.98(\mathrm{~d}, J=9.9 \mathrm{~Hz}, 1 \mathrm{H}), 3.75-3.80(\mathrm{~m}, 2 \mathrm{H}), 3.64-3.71$ (m, $2 \mathrm{H}), 3.59(\mathrm{dd}, J=2.4,9.5 \mathrm{~Hz}, 1 \mathrm{H}), 3.35(\mathrm{dq}, J=1.7,7.1 \mathrm{~Hz}, 1 \mathrm{H}), 3.14-3.19$ (m, $1 \mathrm{H}), 2.97(\mathrm{dd}, J=3.7,10.7 \mathrm{~Hz}, 1 \mathrm{H}), 2.40(\mathrm{~s}, 3 \mathrm{H}), 2.17(\mathrm{~s}, 3 \mathrm{H}), 1.89-2.05$ $(\mathrm{m}, 2 \mathrm{H}), 1.77-1.87(\mathrm{~m}, 1 \mathrm{H}), 1.41(\mathrm{~s}, 9 \mathrm{H}), 1.24-1.30(\mathrm{~m}, 4 \mathrm{H}), 1.22$ (d, $J=7.1 \mathrm{~Hz}, 3 \mathrm{H}), 0.84-0.89(\mathrm{~m}, 3 \mathrm{H}), 0.16(\mathrm{~m}, 9 \mathrm{H}), 0.12(\mathrm{~m}, 9 \mathrm{H}), 0.11$ (m, 9H); MS (ESI) $m / z 794(\mathrm{M}+\mathrm{H})^{+}$.
Synthesis of 7(S)-7-(azetidin-3-ylthio)-7-deoxylincomycin (8)

To a solution of $7(280 \mathrm{mg})$ in $\mathrm{MeOH}(2 \mathrm{ml})$ was added $1 \mathrm{~N}$ hydrochloric acid $(1 \mathrm{ml})$ and the mixture was stirred at room temperature for $20 \mathrm{~min}$. The mixture was diluted with AcOEt and washed with $10 \%$ aqueous $\mathrm{NaHCO}_{3}$. The organic phase was dried over $\mathrm{Na}_{2} \mathrm{SO}_{4}$, filtered and concentrated in vacuo to give white solid $(205 \mathrm{mg})$. Trifluoroacetic acid $(1 \mathrm{ml})$ was added to the solid and stirred at room temperature for $20 \mathrm{~min}$ and concentrated in vacuo. The resulting residue was purified by silica gel column chromatography (AcOEt$\mathrm{MeOH})$ to afford $8(99 \mathrm{mg}, 73 \%)$ as a colorless solid. $[\alpha]_{\mathrm{D}}{ }^{29}+118^{\circ}(c 1.0$, $\left.\mathrm{CHCl}_{3}\right) ;{ }^{1} \mathrm{H} \mathrm{NMR}\left(400 \mathrm{MHz}, \mathrm{CD}_{3} \mathrm{OD}\right) \delta 7.91(\mathrm{~s}, 1 \mathrm{H}), 5.26(\mathrm{~d}, J=5.6 \mathrm{~Hz}, 1 \mathrm{H})$, $4.36-4.50(\mathrm{~m}, 3 \mathrm{H}), 4.21(\mathrm{~d}, J=9.7 \mathrm{~Hz}, 1 \mathrm{H}), 4.12-4.17(\mathrm{~m}, 1 \mathrm{H}), 4.09(\mathrm{dd}$, $J=5.6,10.3 \mathrm{~Hz}, 1 \mathrm{H}), 3.98$ (ddd, $J=3.5,7.4,10.8 \mathrm{~Hz}, 2 \mathrm{H}), 3.78(\mathrm{~d}, J=3.4 \mathrm{~Hz}$, $1 \mathrm{H}), 3.59-3.66(\mathrm{~m}, 1 \mathrm{H}), 3.56(\mathrm{dd}, J=3.4,10.4 \mathrm{~Hz}, 1 \mathrm{H}), 3.36-3.51(\mathrm{~m}, 3 \mathrm{H})$, $2.61(\mathrm{~s}, 3 \mathrm{H}), 2.34-2.45(\mathrm{~m}, 1 \mathrm{H}), 2.34-2.44(\mathrm{~m}, 1 \mathrm{H}), 2.19-2.30(\mathrm{~m}, 1 \mathrm{H}) 2.18(\mathrm{~s}$, $3 \mathrm{H}), 1.96-2.14(\mathrm{~m}, 2 \mathrm{H}), 1.33-1.44(\mathrm{~m}, 4 \mathrm{H}), 1.31(\mathrm{~d}, J=6.8 \mathrm{~Hz}, 3 \mathrm{H}), 0.93$ $(\mathrm{t}, J=7.1 \mathrm{~Hz}, 3 \mathrm{H})$; MS (FAB (fast atom bombardment)) $\mathrm{m} / \mathrm{z} 477(\mathrm{M}+\mathrm{H})^{+}$; high resolution mass spectrometry (HRMS) (FAB) $\mathrm{m} / z$ calcd for $\mathrm{C}_{21} \mathrm{H}_{40} \mathrm{~N}_{3} \mathrm{O}_{5} \mathrm{~S}_{2}$ 478.2409, found $478.2408(\mathrm{M}+\mathrm{H})^{+}$.

\section{7(S)-7-(Azetidin-3-ylthio)-7-deoxy-2,3,4-tris-O-(trimethylsilyl) lincomycin (9)}

To a cold $\left(0^{\circ} \mathrm{C}\right)$ solution of $\mathbf{8}(3.48 \mathrm{~g})$ in pyridine were added trimethylsilyl chloride $(4.59 \mathrm{ml})$ and hexamethyldisilazane $(7.5 \mathrm{ml})$ and the mixture was 
stirred at room temperature for $1 \mathrm{~h}$. The reaction mixture was poured into $10 \%$ aqueous $\mathrm{NaHCO}_{3}$ and extracted with AcOEt. The organic phase was dried over $\mathrm{Na}_{2} \mathrm{SO}_{4}$, filtered and concentrated in vacuo. The resulting residue was dissolved in $\mathrm{MeOH}(30 \mathrm{ml})$ and $6 \mathrm{~N} \mathrm{AcOH}(3.59 \mathrm{ml})$ was added to the solution. After the mixture was stirred at room temperature for $3.5 \mathrm{~h}$, the mixture was poured into $10 \%$ aqueous $\mathrm{NaHCO}_{3}$ and extracted with AcOEt. The organic phase was dried over $\mathrm{Na}_{2} \mathrm{SO}_{4}$, filtered and concentrated in vacuo. The resulting residue was purified by $\mathrm{NH}$ silica gel column chromatography (hexane-AcOEt) to afford 9 $(3.0 \mathrm{~g}, 60 \%)$ as a colorless solid. $[\alpha]_{\mathrm{D}}{ }^{28}+78^{\circ}\left(c\right.$ 1.2, $\left.\mathrm{CHCl}_{3}\right) ;{ }^{1} \mathrm{H}$ NMR $\left(400 \mathrm{MHz}, \mathrm{CDCl}_{3}\right) \delta 7.48(\mathrm{~d}, J=11.0 \mathrm{~Hz}, 1 \mathrm{H}), 5.23(\mathrm{~d}, J=5.6 \mathrm{~Hz}, 1 \mathrm{H}), 4.47$ $(\mathrm{dt}, J=1.8,10.5 \mathrm{~Hz}, 1 \mathrm{H}), 4.17(\mathrm{dd}, J=5.6,9.5 \mathrm{~Hz}, 1 \mathrm{H}), 4.00(\mathrm{~d}, J=10.2 \mathrm{~Hz}$, $1 \mathrm{H}), 3.83-3.90(\mathrm{~m}, 2 \mathrm{H}), 3.73-3.81(\mathrm{~m}, 1 \mathrm{H}), 3.70(\mathrm{~d}, J=2.2 \mathrm{~Hz}, 1 \mathrm{H}), 3.57-3.65$ $(\mathrm{m}, 3 \mathrm{H}), 3.36(\mathrm{dq}, J=1.8,7.1 \mathrm{~Hz}, 1 \mathrm{H}), 3.14-3.20(\mathrm{~m}, 1 \mathrm{H}), 2.98(\mathrm{dd}, J=3.7$, $11 \mathrm{~Hz}, 1 \mathrm{H}), 2.43(\mathrm{~s}, 3 \mathrm{H}), 2.41(\mathrm{~d}, J=6.1 \mathrm{~Hz}, 1 \mathrm{H}), 2.18(\mathrm{~s}, 3 \mathrm{H}), 1.92-2.09$ $(\mathrm{m}, 3 \mathrm{H}), 1.73-1.90(\mathrm{~m}, 1 \mathrm{H}), 1.68(\mathrm{br} s, 2 \mathrm{H}), 1.25-1.32(\mathrm{~m}, 4 \mathrm{H}), 1.23$ (d, $J=7.1 \mathrm{~Hz}, 3 \mathrm{H}), 0.89$ (t, $J=6.9 \mathrm{~Hz}, 3 \mathrm{H}), 0.17$ (s, 9H), 0.14 (s, 9H), 0.12 (s, 9H); MS (ESI) $m / z 694(\mathrm{M}+\mathrm{H})^{+}$.

\section{7(S)-7-[1-(Benzo[d]oxazol-2-yl)azetidin-3-ylthio]-7-deoxylincomycin (10d)}

To a solution of $9(60 \mathrm{mg})$ in $N, N$-dimethylformamide $(500 \mu \mathrm{l})$ were added 2chlorobenzoxazole $(9.9 \mu \mathrm{l})$, triethylamine $(12.1 \mu \mathrm{l})$ and the mixture was stirred at room temperature for $3 \mathrm{~h}$ The mixture was diluted with AcOEt and washed with $10 \%$ aqueous $\mathrm{NaHCO}_{3}$. The organic phase was dried over $\mathrm{Na}_{2} \mathrm{SO}_{4}$, filtered and concentrated in vacuo. To the resulting residue were added $\mathrm{MeOH}(1 \mathrm{ml})$ and $1 \mathrm{~m}$ hydrochloric acid $(1 \mathrm{ml})$ and the reaction mixture was stirred at room temperature for $10 \mathrm{~min}$. The mixture was diluted with AcOEt and washed with $10 \%$ aqueous $\mathrm{NaHCO}_{3}$. The organic phase was dried over $\mathrm{Na}_{2} \mathrm{SO}_{4}$, filtered and concentrated in vacuo. The resulting residue was purified by silica gel column chromatography (AcOEt-MeOH) to afford $10 \mathrm{~d}(51 \mathrm{mg}, 99 \%)$ as a colorless solid. $[\alpha]_{\mathrm{D}}{ }^{28}+103^{\circ}\left(c 0.99, \mathrm{CHCl}_{3}\right)$; H NMR $\left(400 \mathrm{MHz}, \mathrm{CD}_{3} \mathrm{OD}\right) \delta$ 7.29-7.35 $(\mathrm{m}, 2 \mathrm{H}), 7.19(\mathrm{dt}, J=1.1,7.5 \mathrm{~Hz}, 1 \mathrm{H}), 7.09(\mathrm{dt}, J=1.1,7.5 \mathrm{~Hz}, 1 \mathrm{H}), 5.27$ (d, $J=5.6 \mathrm{~Hz}, 1 \mathrm{H}), 4.62-4.72(\mathrm{~m}, 2 \mathrm{H}), 4.33(\mathrm{dd}, J=2.9,9.7 \mathrm{~Hz}, 1 \mathrm{H}), 4.07-4.21$ (m, $5 \mathrm{H}), 3.71-3.75(\mathrm{~m}, 1 \mathrm{H}), 3.57$ (dd, $J=3.4,10.2 \mathrm{~Hz}, 1 \mathrm{H}), 3.52$ (dq, $J=2.9$, $6.8 \mathrm{~Hz}, 1 \mathrm{H}), 3.23(\mathrm{dd}, J=5.6,8.0 \mathrm{~Hz}, 1 \mathrm{H}), 2.99(\mathrm{dd}, J=4.4,10.5 \mathrm{~Hz}, 1 \mathrm{H}), 2.43$ $(\mathrm{s}, 3 \mathrm{H}), 2.17(\mathrm{~s}, 3 \mathrm{H}), 1.95-2.15(\mathrm{~m}, 3 \mathrm{H}), 1.80-1.90(\mathrm{~m}, 1 \mathrm{H}), 1.27-1.38$ (m, 7H), 0.88-0.94 (m, 3H); MS (FAB) $m / z 595(\mathrm{M}+\mathrm{H})^{+}$; HRMS (FAB) $m / z$ calcd for $\mathrm{C}_{28} \mathrm{H}_{43} \mathrm{~N}_{4} \mathrm{O}_{6} \mathrm{~S}_{2}$ 595.2624, found $595.2633(\mathrm{M}+\mathrm{H})^{+}$.

7(S)-7-Deoxy-7-[1-(2-nitrophenyl)azetidin-3-ylthio]lincomycin (10a) Reaction of 9 with 2-fluoronitrobenzene gave 10a as a yellow solid in $57 \%$ yield by a similar procedure to $10 \mathrm{~d}$. $[\alpha]_{\mathrm{D}}{ }^{29}+53^{\circ}\left(c 0.75, \mathrm{CHCl}_{3}\right) ;{ }^{1} \mathrm{H}$ NMR $\left(400 \mathrm{MHz}, \mathrm{CD}_{3} \mathrm{OD}\right) \delta 7.78(\mathrm{dd}, J=1.6,8.3 \mathrm{~Hz}, 1 \mathrm{H}), 7.45$ (ddd, $J=1.6,7.1$, $8.5 \mathrm{~Hz}, 1 \mathrm{H}), 6.80(\mathrm{ddd}, J=1.2,7.1,8.3 \mathrm{~Hz}, 1 \mathrm{H}), 6.72(\mathrm{dd}, J=1.2,8.5 \mathrm{~Hz}, 1 \mathrm{H})$, $5.26(\mathrm{~d}, J=5.6 \mathrm{~Hz}, 1 \mathrm{H}), 4.39(\mathrm{t}, J=8.2 \mathrm{~Hz}, 1 \mathrm{H}), 4.27-4.36(\mathrm{~m}, 2 \mathrm{H}), 4.16$ $(\mathrm{d}, J=9.7 \mathrm{~Hz}, 1 \mathrm{H}), 4.09(\mathrm{dd}, J=5.6,10.2 \mathrm{~Hz}, 1 \mathrm{H}), 3.91-4.01(\mathrm{~m}, 1 \mathrm{H})$, $3.72-3.78(\mathrm{~m}, 2 \mathrm{H}), 3.70-3.72(\mathrm{~m}, 1 \mathrm{H}), 3.56(\mathrm{dd}, J=3.2,10.2 \mathrm{~Hz}, 1 \mathrm{H}), 3.51$ $(\mathrm{dq}, J=2.7,7.0 \mathrm{~Hz}, 1 \mathrm{H}), 3.23(\mathrm{dd}, J=5.6,8.0 \mathrm{~Hz}, 1 \mathrm{H}), 2.99(\mathrm{dd}, J=4.6$, $10.7 \mathrm{~Hz}, 1 \mathrm{H}), 2.41(\mathrm{~s}, 3 \mathrm{H}), 2.15(\mathrm{~s}, 3 \mathrm{H}), 2.03-2.14(\mathrm{~m}, 2 \mathrm{H}), 1.93-2.03(\mathrm{~m}, 1 \mathrm{H})$, $1.84(\mathrm{td}, J=10.2,12.8 \mathrm{~Hz}, 1 \mathrm{H}), 1.29-1.35(\mathrm{~m}, 7 \mathrm{H}), 0.87-0.94(\mathrm{~m}, 3 \mathrm{H})$; MS (FAB) $m / z 599(\mathrm{M}+\mathrm{H})^{+}$; HRMS (FAB) $\mathrm{m} / z$ calcd for $\mathrm{C}_{27} \mathrm{H}_{43} \mathrm{~N}_{4} \mathrm{O}_{7} \mathrm{~S}_{2}$ 599.2573, found $599.2572(\mathrm{M}+\mathrm{H})^{+}$.

7(S)-7-Deoxy-7-[1-(4-nitrophenyl)azetidin-3-ylthio]lincomycin (10b) Reaction of 9 with 4 -fluoronitrobenzene gave $10 \mathrm{~b}$ as a yellow solid in $56 \%$ yield by a similar procedure to $10 \mathrm{~d}$. $[\alpha]_{\mathrm{D}}{ }^{30}+94^{\circ}\left(\right.$ c $\left.0.87, \mathrm{CHCl}_{3}\right) ;{ }^{1} \mathrm{H}$ NMR $\left(400 \mathrm{MHz}, \mathrm{CD}_{3} \mathrm{OD}\right) \quad \delta \quad 8.06-8.12(\mathrm{~m}, 2 \mathrm{H}), 6.40-6.46(\mathrm{~m}, 2 \mathrm{H}), \quad 5.27$ $(\mathrm{d}, J=5.4 \mathrm{~Hz}, 1 \mathrm{H}), 4.50(\mathrm{t}, J=8.0 \mathrm{~Hz}, 1 \mathrm{H}), 4.45(\mathrm{t}, J=8.0 \mathrm{~Hz}, 1 \mathrm{H}), 4.33$ (dd, $J=2.7,9.7 \mathrm{~Hz}, 1 \mathrm{H}), 4.19(\mathrm{~d}, J=9.7 \mathrm{~Hz}, 1 \mathrm{H}), 4.05-4.13(\mathrm{~m}, 2 \mathrm{H}), 3.84-3.91$ (m, $2 \mathrm{H}), 3.71-3.74(\mathrm{~m}, 1 \mathrm{H}), 3.57(\mathrm{dd}, J=3.2,10.2 \mathrm{~Hz}, 1 \mathrm{H}), 3.52(\mathrm{dq}, J=2.7$, $7.3 \mathrm{~Hz}, 1 \mathrm{H}), 3.23(\mathrm{dd}, J=5.5,7.9 \mathrm{~Hz}, 1 \mathrm{H}), 3.00(\mathrm{dd}, J=4.5,10.6 \mathrm{~Hz}, 1 \mathrm{H})$, $2.41(\mathrm{~s}, 3 \mathrm{H}), 2.16(\mathrm{~s}, 3 \mathrm{H}), 2.04-2.14(\mathrm{~m}, 2 \mathrm{H}), 1.94-2.04(\mathrm{~m}, 1 \mathrm{H}), 1.85$ (td, $J=10.2,13.0 \mathrm{~Hz}, 1 \mathrm{H}), 1.27-1.37(\mathrm{~m}, 7 \mathrm{H}), 0.87-0.94(\mathrm{~m}, 3 \mathrm{H})$; MS (FAB) $m / z 599(\mathrm{M}+\mathrm{H})^{+}$; HRMS (FAB) $\mathrm{m} / z$ calcd for $\mathrm{C}_{27} \mathrm{H}_{43} \mathrm{~N}_{4} \mathrm{O}_{7} \mathrm{~S}_{2} 599.2573$, found $599.2567(\mathrm{M}+\mathrm{H})^{+}$. 
7(S)-7-[1-(4-Aminophenyl)azetidin-3-ylthio]-7-deoxylincomycin (10c) To a solution of $\mathbf{1 0 b}(127 \mathrm{mg})$ in $\mathrm{MeOH}(4 \mathrm{ml})$ was added $\mathrm{PtO}_{2}(77.2 \mathrm{mg})$ and the mixture was stirred in hydrogen atmosphere at room temperature for $1 \mathrm{~h}$. The mixture was filtered through Celite and the filtrate was concentrated in vacuo. The resulting residue was purified by silica gel column chromatography (AcOEt-MeOH) to afford a colorless solid $(77 \mathrm{mg}, 64 \%)$. $[\alpha]_{\mathrm{D}}{ }^{30}+104^{\circ}(c 1.2$, $\left.\mathrm{CHCl}_{3}\right) ;{ }^{1} \mathrm{H}$ NMR $\left(400 \mathrm{MHz}, \mathrm{CD}_{3} \mathrm{OD}\right) \delta 6.64-6.75(\mathrm{~m}, 2 \mathrm{H}), 6.33-6.44$ $(\mathrm{m}, 2 \mathrm{H}), 5.27(\mathrm{~d}, J=5.6 \mathrm{~Hz}, 1 \mathrm{H}), 4.28(\mathrm{dd}, J=2.4,9.7 \mathrm{~Hz}, 1 \mathrm{H}), 4.18-4.25$ $(\mathrm{m}, 1 \mathrm{H}), 4.16(\mathrm{~d}, J=9.7 \mathrm{~Hz}, 1 \mathrm{H}), 4.09$ (dd, $J=5.6,10.2 \mathrm{~Hz}, 2 \mathrm{H}), 3.89-3.98$ (m, $1 \mathrm{H}), 3.70(\mathrm{~d}, J=3.2 \mathrm{~Hz}, 1 \mathrm{H}), 3.56(\mathrm{dd}, J=3.2,10.2 \mathrm{~Hz}, 2 \mathrm{H}), 3.51-3.54$ $(\mathrm{m}, 1 \mathrm{H}), 3.49$ (dq, $J=2.4,7.1 \mathrm{~Hz}, 1 \mathrm{H}), 3.23(\mathrm{dd}, J=5.5,7.7 \mathrm{~Hz}, 1 \mathrm{H}), 3.00$ (dd, $J=4.5,10.5 \mathrm{~Hz}, 1 \mathrm{H}), 2.42(\mathrm{~s}, 3 \mathrm{H}), 2.17(\mathrm{~s}, 3 \mathrm{H}), 2.03-2.14(\mathrm{~m}, 2 \mathrm{H})$, $1.94-2.03(\mathrm{~m}, 1 \mathrm{H}), 1.85(\mathrm{td}, J=10.2,12.8 \mathrm{~Hz}, 1 \mathrm{H}), 1.29-1.36(\mathrm{~m}, 7 \mathrm{H})$, $0.87-0.95(\mathrm{~m}, 3 \mathrm{H})$; MS (FAB) $\mathrm{m} / z 569(\mathrm{M}+\mathrm{H})^{+}$; HRMS (FAB) $\mathrm{m} / z$ calcd for $\mathrm{C}_{27} \mathrm{H}_{45} \mathrm{~N}_{4} \mathrm{O}_{5} \mathrm{~S}_{2}$ 569.2831, found $569.2838(\mathrm{M}+\mathrm{H})^{+}$.

\section{7(S)-7-Deoxy-7-[1-(4,5-dihydrothiazol-2-yl)azetidin-3-ylthio] lincomycin (10e)}

To a solution of $6(150 \mathrm{mg})$ and $\mathrm{K}_{2} \mathrm{CO}_{3}(88.7 \mathrm{mg})$ in $\mathrm{N}, \mathrm{N}$-dimethylformamide $(1.5 \mathrm{ml})$ was added 3-(4,5-dihydrothiazol-2-yl)azetidine-1-thiol hydrochloride $\left(90.2 \mathrm{mg}\right.$ ) and the mixture was stirred at $80^{\circ} \mathrm{C}$ for $5 \mathrm{~h}$. After cooled to room temperature, the mixture was diluted with AcOEt and washed with brine. The organic phase was dried over $\mathrm{Na}_{2} \mathrm{SO}_{4}$, filtered and concentrated in vacuo. The residue was purified by silica gel column chromatography (hexane-AcOEt) to give a colorless solid ( $95 \mathrm{mg}$ ). To a solution of the compound obtained above $(50 \mathrm{mg})$ in $\mathrm{MeOH}$ was added $1 \mathrm{~m}$ hydrochloric acid $(1 \mathrm{ml})$ and the reaction mixture was stirred at room temperature for $5 \mathrm{~min}$. The mixture was diluted with AcOEt and extracted with $\mathrm{H}_{2} \mathrm{O}$. The aqueous phase was neutralized with $10 \%$ aqueous $\mathrm{NaHCO}_{3}$ and extracted with AcOEt. The organic phase was dried over $\mathrm{Na}_{2} \mathrm{SO}_{4}$, filtered and concentrated in vacuo to afford $10 \mathrm{e}(30 \mathrm{mg}, 47 \%)$ as a colorless solid. $[\alpha]_{\mathrm{D}}{ }^{28}+103^{\circ}\left(c 0.99, \mathrm{CHCl}_{3}\right) ;{ }^{1} \mathrm{H} \mathrm{NMR}\left(400 \mathrm{MHz}, \mathrm{CD}_{3} \mathrm{OD}\right) \delta$ $5.26(\mathrm{~d}, J=5.6 \mathrm{~Hz}, 1 \mathrm{H}), 4.40(\mathrm{t}, J=8.0 \mathrm{~Hz}, 1 \mathrm{H}), 4.35(\mathrm{t}, J=8.2 \mathrm{~Hz}, 1 \mathrm{H}), 4.30$ (dd, $J=2.6,9.6 \mathrm{~Hz}, 1 \mathrm{H}), 4.15(\mathrm{~d}, J=9.6 \mathrm{~Hz}, 1 \mathrm{H}), 4.09(\mathrm{dd}, J=5.6,10.2 \mathrm{~Hz}$, $1 \mathrm{H}), 3.98(\mathrm{tt}, J=5.5,7.8 \mathrm{~Hz}, 1 \mathrm{H}), 3.94(\mathrm{t}, J=7.5 \mathrm{~Hz}, 2 \mathrm{H}), 3.79-3.85(\mathrm{~m}, 2 \mathrm{H})$, $3.69-3.72(\mathrm{~m}, 1 \mathrm{H}), 3.56(\mathrm{dd}, J=3.2,10.2 \mathrm{~Hz}, 1 \mathrm{H}), 3.47(\mathrm{dq}, J=2.6,7.1 \mathrm{~Hz}$, $1 \mathrm{H}), 3.38(\mathrm{t}, J=7.5 \mathrm{~Hz}, 2 \mathrm{H}), 3.24(\mathrm{dd}, J=5.5,7.9 \mathrm{~Hz}, 1 \mathrm{H}), 2.99(\mathrm{dd}, J=4.6$, $10.7 \mathrm{~Hz}, 1 \mathrm{H}), 2.42(\mathrm{~s}, 3 \mathrm{H}), 2.19(\mathrm{~s}, 3 \mathrm{H}), 2.05-2.18(\mathrm{~m}, 2 \mathrm{H}), 1.95-2.03(\mathrm{~m}, 1 \mathrm{H})$, $1.85(\mathrm{td}, J=10.2,12.8 \mathrm{~Hz}, 1 \mathrm{H}), 1.31-1.37(\mathrm{~m}, 4 \mathrm{H}), 1.29(\mathrm{~d}, J=7.1 \mathrm{~Hz}, 3 \mathrm{H})$, 0.88-0.95 (m, 3H); MS (FAB) $\mathrm{m} / z 563(\mathrm{M}+\mathrm{H})^{+}$; HRMS (FAB) $\mathrm{m} / z$ calcd for $\mathrm{C}_{24} \mathrm{H}_{43} \mathrm{~N}_{4} \mathrm{O}_{5} \mathrm{~S}_{2}$ 563.2396, found $563.2388(\mathrm{M}+\mathrm{H})^{+}$.

\section{7(S)-7-Deoxy-7-\{1-[2-(dimethylaminocarbonyl)ethyl]azetidin-3- ylthio\}lincomycin (11b)}

To a solution of $9(60 \mathrm{mg})$ in EtOH $(1 \mathrm{ml})$ was added $N, N$-dimethylacrylamide $(8.9 \mu \mathrm{l})$ and the mixture was stirred at room temperature for $15 \mathrm{~min}$ and at $50{ }^{\circ} \mathrm{C}$ for $3 \mathrm{~h}$. The mixture was concentrated in vacuo and the residue was dissolved in $\mathrm{MeOH}(1 \mathrm{ml})$ and $1 \mathrm{~m}$ hydrochloric acid $(1 \mathrm{ml})$ was added to the solution. The mixture was stirred at room temperature for $10 \mathrm{~min}$ and diluted with AcOEt and extracted with $\mathrm{H}_{2} \mathrm{O}$. The aqueous phase was neutralized with $10 \%$ aqueous $\mathrm{NaHCO}_{3}$ and extracted with AcOEt. The organic phase was dried over $\mathrm{Na}_{2} \mathrm{SO}_{4}$, filtered and concentrated in vacuo to afford $11 \mathbf{b}(37 \mathrm{mg}, 74 \%)$ as a colorless solid. $[\alpha]_{\mathrm{D}}{ }^{29}+90^{\circ}\left(c\right.$ 1.1, $\left.\mathrm{CHCl}_{3}\right) ;{ }^{1} \mathrm{H}$ NMR $\left(400 \mathrm{MHz}, \mathrm{CD}_{3} \mathrm{OD}\right)$ $\delta 5.26(\mathrm{~d}, J=5.6 \mathrm{~Hz}, 1 \mathrm{H}), 4.23(\mathrm{dd}, J=2.4,9.7 \mathrm{~Hz}, 1 \mathrm{H}), 4.14(\mathrm{~d}, J=9.7 \mathrm{~Hz}, \mathrm{H})$, 4.09 (dd, $J=5.6,10.2 \mathrm{~Hz}, 1 \mathrm{H}), 3.62-3.82(\mathrm{~m}, 5 \mathrm{H}), 3.55(\mathrm{dd}, J=3.2,10.2 \mathrm{~Hz}$, $1 \mathrm{H}), 3.42(\mathrm{dq}, J=2.4,6.9 \mathrm{~Hz}, 1 \mathrm{H}), 3.19-3.26(\mathrm{~m}, 1 \mathrm{H}), 3.02-3.09(\mathrm{~m}, 4 \mathrm{H})$, 2.93-3.02 (m, 1H), $2.91(\mathrm{~s}, 3 \mathrm{H}), 2.74(\mathrm{t}, J=7.3 \mathrm{~Hz}, 2 \mathrm{H}), 2.42(\mathrm{~s}, 3 \mathrm{H}), 2.39$ (t, $J=7.3 \mathrm{~Hz}, 2 \mathrm{H}), 2.18(\mathrm{~s}, 3 \mathrm{H}), 2.03-2.16(\mathrm{~m}, 2 \mathrm{H}), 1.94-2.02(\mathrm{~m}, 1 \mathrm{H}), 1.84$ $(\mathrm{td}, J=10.0,12.9 \mathrm{~Hz}, 1 \mathrm{H}), 1.30-1.37(\mathrm{~m}, 4 \mathrm{H}), 1.28(\mathrm{~d}, J=6.9 \mathrm{~Hz}, 3 \mathrm{H})$, $0.87-0.95(\mathrm{~m}, 3 \mathrm{H})$; MS (FAB) $\mathrm{m} / z 577(\mathrm{M}+\mathrm{H})^{+}$; HRMS (FAB) $\mathrm{m} / z$ calcd for $\mathrm{C}_{26} \mathrm{H}_{49} \mathrm{~N}_{4} \mathrm{O}_{6} \mathrm{~S}_{2}$ 577.3094, found $577.3089(\mathrm{M}+\mathrm{H})^{+}$.

\section{7(S)-7-Deoxy-7-\{1-[2-(methoxycarbonyl)ethyl]azetidin-3-ylthio\} lincomycin (11a)}

Reaction of 9 with methyl 3-butenoate gave 11a as a colorless solid in $74 \%$ yield by a similar procedure to $1 \mathbf{1 b}$. $[\alpha]_{\mathrm{D}}{ }^{30}+86^{\circ}\left(c 1.1, \mathrm{CHCl}_{3}\right) ;{ }^{1} \mathrm{H} \mathrm{NMR}(400 \mathrm{MHz}$,
$\left.\mathrm{CD}_{3} \mathrm{OD}\right) \delta 5.25(\mathrm{~d}, J=5.6 \mathrm{~Hz}, 1 \mathrm{H}), 4.24(\mathrm{dd}, J=2.5,9.7 \mathrm{~Hz}, 1 \mathrm{H}), 4.14$ (d, $J=9.7 \mathrm{~Hz}, 1 \mathrm{H}), 4.08$ (dd, $J=5.6,10.4 \mathrm{~Hz}, 1 \mathrm{H}), 3.61-3.82(\mathrm{~m}, 7 \mathrm{H}), 3.55$ $(\mathrm{dd}, J=3.2,10.4 \mathrm{~Hz}, 1 \mathrm{H}), 3.41(\mathrm{dq}, J=2.5,7.0 \mathrm{~Hz}, 1 \mathrm{H}), 3.24(\mathrm{dd}, J=5.2$, $8.0 \mathrm{~Hz}, 1 \mathrm{H}), 2.96-3.05(\mathrm{~m}, 3 \mathrm{H}), 2.75(\mathrm{t}, J=7.2 \mathrm{~Hz}, 2 \mathrm{H}), 2.42(\mathrm{~s}, 3 \mathrm{H}), 2.36$ $(\mathrm{t}, J=7.2 \mathrm{~Hz}, 2 \mathrm{H}), 2.17(\mathrm{~s}, 3 \mathrm{H}), 2.04-2.16(\mathrm{~m}, 2 \mathrm{H}), 1.93-2.03(\mathrm{~m}, 1 \mathrm{H})$, $1.80-1.90(\mathrm{~m}, 1 \mathrm{H}), 1.30-1.37(\mathrm{~m}, 4 \mathrm{H}), 1.28(\mathrm{~d}, J=7.0 \mathrm{~Hz}, 3 \mathrm{H}), 0.87-0.95$ $(\mathrm{m}, 3 \mathrm{H})$; MS (FAB) $\mathrm{m} / z 564(\mathrm{M}+\mathrm{H})^{+}$; HRMS (FAB) $\mathrm{m} / z$ calcd for $\mathrm{C}_{25} \mathrm{H}_{46} \mathrm{~N}_{3} \mathrm{O}_{7} \mathrm{~S}_{2}$ 564.2777, found $564.2770(\mathrm{M}+\mathrm{H})^{+}$.

\section{7(S)-7-Deoxy-7-\{1-[2-(morpholin-4-yl)ethyl]azetidin-3-ylthio\} lincomycin (11c)}

Reaction of 9 with 4-acryloylmorpholine gave 11c as a colorless solid in $70 \%$ yield by a similar procedure to $11 \mathbf{b}$. $[\alpha]_{\mathrm{D}}{ }^{29}+91^{\circ}\left(\mathrm{c} 1.1, \mathrm{CHCl}_{3}\right) ;{ }^{1} \mathrm{H}$ NMR $\left(400 \mathrm{MHz}, \mathrm{CD}_{3} \mathrm{OD}\right) \delta 5.26(\mathrm{~d}, J=5.6 \mathrm{~Hz}, 1 \mathrm{H}), 4.24(\mathrm{dd}, J=2.4,10.1 \mathrm{~Hz}, 1 \mathrm{H})$, $4.14(\mathrm{~d}, J=10.1 \mathrm{~Hz}, 1 \mathrm{H}), 4.08(\mathrm{dd}, J=5.6,10.7 \mathrm{~Hz}, 1 \mathrm{H}), 3.71-3.81(\mathrm{~m}, 2 \mathrm{H})$, $3.61-3.71(\mathrm{~m}, 6 \mathrm{H}), 3.49-3.58(\mathrm{~m}, 5 \mathrm{H}), 3.42(\mathrm{dq}, J=2.4,6.9 \mathrm{~Hz}, 1 \mathrm{H}), 3.20-3.26$ (m, $1 \mathrm{H}), 3.01-3.09(\mathrm{~m}, 2 \mathrm{H}), 2.99(\mathrm{dd}, J=4.6,10.5 \mathrm{~Hz}, 1 \mathrm{H}), 2.75(\mathrm{t}, J=7.6 \mathrm{~Hz}$, $2 \mathrm{H}), 2.42(\mathrm{~s}, 3 \mathrm{H}), 2.41(\mathrm{t}, J=7.6 \mathrm{~Hz}, 2 \mathrm{H}), 2.18(\mathrm{~s}, 3 \mathrm{H}), 2.05-2.16(\mathrm{~m}, 2 \mathrm{H})$, 1.94-1.99 (m, $1 \mathrm{H}), 1.80-1.89(\mathrm{~m}, 1 \mathrm{H}), 1.30-1.37(\mathrm{~m}, 4 \mathrm{H}), 1.28(\mathrm{~d}, J=6.9 \mathrm{~Hz}$, $3 \mathrm{H}), 0.88-0.95(\mathrm{~m}, 3 \mathrm{H})$; MS (FAB) $\mathrm{m} / z 619(\mathrm{M}+\mathrm{H})^{+}$; HRMS (FAB) $\mathrm{m} / z$ calcd for $\mathrm{C}_{28} \mathrm{H}_{51} \mathrm{~N}_{4} \mathrm{O}_{7} \mathrm{~S}_{2}$ 619.3199, found $619.3192(\mathrm{M}+\mathrm{H})^{+}$.

\section{7(S)-7-Deoxy-7-[1-(dimethylaminocarbonyl)azetidin-3-ylthio] lincomycin (12a)}

To a solution of $9(100 \mathrm{mg})$ in $\mathrm{CHCl}_{3}(700 \mu \mathrm{l})$ were added triethylamine $(20.2 \mu \mathrm{l})$, dimethylcarbamoyl chloride $(13.2 \mu \mathrm{l})$ and $N, N$-dimethylaminopyridine $(17.6 \mathrm{mg})$ and the mixture was stirred at room temperature for $3.5 \mathrm{~h}$. The mixture was diluted with AcOEt and washed with $10 \%$ aqueous $\mathrm{NaHCO}_{3}$. The organic phase was dried over $\mathrm{Na}_{2} \mathrm{SO}_{4}$, filtered and concentrated in vacuo. The residue was purified by silica gel column chromatography (hexane-AcOEt) to give a colorless solid $(95 \mathrm{mg})$. To a stirred solution of the compound obtained above $(95 \mathrm{mg})$ in $\mathrm{MeOH}(1 \mathrm{ml})$ was added $1 \mathrm{~m}$ hydrochloric acid $(1 \mathrm{ml})$ and the reaction mixture was stirred at room temperature for $10 \mathrm{~min}$. The mixture was diluted with AcOEt and extracted with $\mathrm{H}_{2} \mathrm{O}$. The aqueous phase was neutralized with $10 \%$ aqueous $\mathrm{NaHCO}_{3}$ and extracted with AcOEt. The organic phase was dried over $\mathrm{Na}_{2} \mathrm{SO}_{4}$, filtered and concentrated in vacuo to afford 12a $(55 \mathrm{mg}, 70 \%)$ as a colorless solid. $[\alpha]_{\mathrm{D}}{ }^{29}+66^{\circ}\left(c\right.$ 1.1, $\left.\mathrm{CHCl}_{3}\right)$; ${ }^{1} \mathrm{H}$ NMR $\left(400 \mathrm{MHz}, \mathrm{CD}_{3} \mathrm{OD}\right) \delta 5.26(\mathrm{~d}, J=5.6 \mathrm{~Hz}, 1 \mathrm{H}), 4.32-4.42(\mathrm{~m}, 2 \mathrm{H})$, 4.29 (dd, $J=2.6,9.7 \mathrm{~Hz}, 1 \mathrm{H}), 4.15$ (dd, $J=0.73,9.7 \mathrm{~Hz}, 1 \mathrm{H}), 4.09$ (dd, $J=5.6$, $10.4 \mathrm{~Hz}, 1 \mathrm{H}), 3.80-3.88(\mathrm{~m}, 3 \mathrm{H}), 3.69-3.71(\mathrm{~m}, 1 \mathrm{H}), 3.56(\mathrm{dd}, J=3.2,10.4 \mathrm{~Hz}$, $1 \mathrm{H}), 3.46(\mathrm{dq}, J=2.6,7.1 \mathrm{~Hz}, 1 \mathrm{H}), 3.24(\mathrm{dd}, J=5.5,7.9 \mathrm{~Hz}, 1 \mathrm{H}), 2.99$ (dd, $J=4.6,10.5 \mathrm{~Hz}, 1 \mathrm{H}), 2.84(\mathrm{~s}, 6 \mathrm{H}), 2.42(\mathrm{~s}, 3 \mathrm{H}), 2.19$ (s, 3H), 2.04-2.16 $(\mathrm{m}, 2 \mathrm{H}), 1.94-2.02(\mathrm{~m}, 1 \mathrm{H}), 1.84(\mathrm{td}, J=10.1,12.9 \mathrm{~Hz}, 1 \mathrm{H}), 1.31-1.37$ (m, 4H), 1.29 (d, J=7.1 Hz, 3H), 0.89-0.94 (m, 3H); MS (FAB) m/z 549 $(\mathrm{M}+\mathrm{H})^{+}$; HRMS (FAB) $m / z$ calcd for $\mathrm{C}_{26} \mathrm{H}_{44} \mathrm{~N}_{5} \mathrm{O}_{6} \mathrm{~S}_{3}$ 549.2781, found $549.2782(\mathrm{M}+\mathrm{H})^{+}$.

\section{7(S)-7-Deoxy-7-\{1-[(morpholin-4-yl)carbonyl]azetidin-3-ylthio $\}$ lincomycin (12c)}

Reaction of 9 with 4-morpholinylcarbonyl chloride gave $12 \mathrm{c}$ as a colorless solid in $70 \%$ yield by a similar procedure to $12 \mathrm{a}$. $[\alpha]_{\mathrm{D}}{ }^{29}+69^{\circ}\left(c 0.86, \mathrm{CHCl}_{3}\right) ;{ }^{1} \mathrm{H}$ NMR (400 MHz, CD 3 OD) $\delta 5.26(\mathrm{~d}, J=5.6 \mathrm{~Hz}, 1 \mathrm{H}), 4.33-4.45(\mathrm{~m}, 2 \mathrm{H}), 4.29$ $(\mathrm{dd}, J=2.7,9.5 \mathrm{~Hz}, 1 \mathrm{H}), 4.15(\mathrm{~d}, J=9.5 \mathrm{~Hz}, 1 \mathrm{H}), 4.09(\mathrm{dd}, J=5.6,10.4 \mathrm{~Hz}$, $1 \mathrm{H}), 3.83-3.91(\mathrm{~m}, 3 \mathrm{H}), 3.70(\mathrm{~d}, J=3.3 \mathrm{~Hz}, 1 \mathrm{H}), 3.59-3.64(\mathrm{~m}, 4 \mathrm{H}), 3.55$ (dd, $J=3.3,10.4 \mathrm{~Hz}, 1 \mathrm{H}), 3.46(\mathrm{dq}, J=2.7,7.0 \mathrm{~Hz}, 1 \mathrm{H}), 3.27-3.33(\mathrm{~m}, 4 \mathrm{H})$, $3.23(\mathrm{dd}, J=5.2,7.9 \mathrm{~Hz}, 1 \mathrm{H}), 2.99(\mathrm{dd}, J=4.6,10.7 \mathrm{~Hz}, 1 \mathrm{H}), 2.42(\mathrm{~s}, 3 \mathrm{H})$, $2.18(\mathrm{~s}, 3 \mathrm{H}), 2.04-2.17(\mathrm{~m}, 2 \mathrm{H}), 1.94-2.02(\mathrm{~m}, 1 \mathrm{H}), 1.79-1.89(\mathrm{~m}, 1 \mathrm{H})$, $1.31-1.37(\mathrm{~m}, 4 \mathrm{H}), 1.29$ (d, $J=7.0 \mathrm{~Hz}, 3 \mathrm{H}), 0.88-0.95$ (m, 3H); MS (FAB) $\mathrm{m} / \mathrm{z}$ $591(\mathrm{M}+\mathrm{H})^{+}$; HRMS (FAB) $\mathrm{m} / \mathrm{z}$ calcd for $\mathrm{C}_{26} \mathrm{H}_{47} \mathrm{~N}_{4} \mathrm{O}_{7} \mathrm{~S}_{2}$ 591.2886, found $591.2891(\mathrm{M}+\mathrm{H})^{+}$.

\section{7(S)-7-Deoxy-7-[1-(phenylcarbonyl)azetidin-3-ylthio]lincomycin} (12d)

Reaction of 9 with benzoyl chloride gave 12d as a colorless solid in $67 \%$ yield by a similar procedure to $12 \mathrm{a}$. $[\alpha]_{\mathrm{D}}{ }^{30}+90^{\circ}\left(c 0.74, \mathrm{CHCl}_{3}\right) ;{ }^{1} \mathrm{H}$ NMR 
$\left(400 \mathrm{MHz}, \mathrm{CD}_{3} \mathrm{OD}\right) \delta$ 7.84-7.90 (m, 2H), 7.72-7.79 (m, 1H), 7.65-7.72 $(\mathrm{m}, 2 \mathrm{H}), 5.21(\mathrm{~d}, J=5.6 \mathrm{~Hz}, 1 \mathrm{H}), 4.22(\mathrm{dd}, J=2.7,9.3 \mathrm{~Hz}, 1 \mathrm{H}), 4.19-4.11$ $(\mathrm{m}, 2 \mathrm{H}), 4.06(\mathrm{dd}, J=5.6,10.3 \mathrm{~Hz}, 1 \mathrm{H}), 4.05-4.02(\mathrm{~m}, 1 \mathrm{H}), 3.68-3.77(\mathrm{~m}, 1 \mathrm{H})$, $3.66(\mathrm{~d}, J=3.2 \mathrm{~Hz}, 1 \mathrm{H}), 3.54-3.58(\mathrm{~m}, 2 \mathrm{H}), 3.52(\mathrm{dd}, J=3.2,10.3 \mathrm{~Hz}, 1 \mathrm{H})$, $3.33(\mathrm{dq}, J=2.7,6.8 \mathrm{~Hz}, 1 \mathrm{H}), 3.19$ (dd, $J=5.2,7.9 \mathrm{~Hz}, 1 \mathrm{H}), 2.94$ (dd, $J=4.6$, $10.7 \mathrm{~Hz}, 1 \mathrm{H}), 2.34(\mathrm{~s}, 3 \mathrm{H}), 2.10-2.16(\mathrm{~m}, 1 \mathrm{H}), 2.08(\mathrm{~s}, 3 \mathrm{H}), 2.02-2.07(\mathrm{~m}, 1 \mathrm{H})$, $1.89-2.00(\mathrm{~m}, 1 \mathrm{H}), 1.76-1.87(\mathrm{~m}, 1 \mathrm{H}), 1.26-1.35(\mathrm{~m}, 4 \mathrm{H}), 1.16-1.21(\mathrm{~m}, 3 \mathrm{H})$, 0.87-0.94 (m, 3H); MS (FAB) $m / z 618(\mathrm{M}+\mathrm{H})^{+}$; HRMS (FAB) $\mathrm{m} / z$ calcd for $\mathrm{C}_{27} \mathrm{H}_{44} \mathrm{~N}_{3} \mathrm{O}_{7} \mathrm{~S}_{3}$ 618.2341, found $618.2340(\mathrm{M}+\mathrm{H})^{+}$.

\section{7(S)-7-Deoxy-7-[1-(2-nitrophenylcarbonyl)azetidin-3-ylthio] lincomycin (12e)}

Reaction of 9 with 2-nitrobenzoyl chloride gave 12e as a yellow solid in $72 \%$ yield by a similar procedure to $12 \mathrm{a}$. $[\alpha]_{\mathrm{D}}{ }^{30}+88^{\circ}\left(\right.$ c $\left.1.0, \mathrm{CHCl}_{3}\right) ;{ }^{1} \mathrm{H}$ NMR $\left(400 \mathrm{MHz}, \mathrm{CD}_{3} \mathrm{OD}\right) \delta 8.17-8.23(\mathrm{~m}, 1 \mathrm{H}), 7.79-7.85(\mathrm{~m}, 1 \mathrm{H}), 7.69-7.74$ $(\mathrm{m}, 1 \mathrm{H}), 7.52-7.57(\mathrm{~m}, 1 \mathrm{H}), 5.19-5.28(\mathrm{~m}, 1 \mathrm{H}), 4.55-4.66(\mathrm{~m}, 1 \mathrm{H}), 4.25-4.41$ $(\mathrm{m}, 2 \mathrm{H}), 3.98-4.20(\mathrm{~m}, 3 \mathrm{H}), 3.78-3.86(\mathrm{~m}, 1 \mathrm{H}), 3.68-3.73(\mathrm{~m}, 1 \mathrm{H}), 3.41-3.63$ $(\mathrm{m}, 2 \mathrm{H}), 3.17-3.27(\mathrm{~m}, 1 \mathrm{H}), 3.17-3.27(\mathrm{~m}, 1 \mathrm{H}), 2.93-3.02(\mathrm{~m}, 1 \mathrm{H}), 2.36-2.44$ $(\mathrm{m}, 3 \mathrm{H}), 2.03-2.24(\mathrm{~m}, 5 \mathrm{H}), 1.92-2.03(\mathrm{~m}, 1 \mathrm{H}), 1.78-1.90(\mathrm{~m}, 1 \mathrm{H}), 1.22-1.37$ (m, 7H), 0.87-0.95 (m, 3H); MS (FAB) $\mathrm{m} / z 627(\mathrm{M}+\mathrm{H})^{+}$; HRMS (FAB) $\mathrm{m} / z$ calcd for $\mathrm{C}_{28} \mathrm{H}_{43} \mathrm{~N}_{4} \mathrm{O}_{8} \mathrm{~S}_{2}$ 627.2522, found $627.2516(\mathrm{M}+\mathrm{H})^{+}$.

\section{7(S)-7-Deoxy-7-[1-(piperidin-1-yl)azetidin-3-ylthio]lincomycin}

(12b)

To a cold $\left(0{ }^{\circ} \mathrm{C}\right)$ solution of $9(80 \mathrm{mg})$ in $\mathrm{CH}_{2} \mathrm{Cl}_{2}(0.5 \mathrm{ml})$ were added piperidine $(12.5 \mu \mathrm{l})$, pyridine $(20.5 \mu \mathrm{l})$ and triphosgene $(12.6 \mathrm{mg})$, the mixture was stirred at room temperature for $1 \mathrm{~h}$. The mixture was diluted with AcOEt and washed with $10 \%$ aqueous $\mathrm{NaHCO}_{3}$. The organic phase was dried over $\mathrm{Na}_{2} \mathrm{SO}_{4}$, filtered and concentrated in vacuo. The residue was purified by silica gel column chromatography (hexane-AcOEt) to give a colorless amorphous $(22 \mathrm{mg})$. To a stirred solution of the compound obtained above $(22 \mathrm{mg})$ in $\mathrm{MeOH}(1 \mathrm{ml})$ was added $1 \mathrm{~m}$ hydrochloric acid $(1 \mathrm{ml})$ and the reaction mixture was stirred at room temperature for $10 \mathrm{~min}$. The mixture was diluted with AcOEt and washed with $10 \%$ aqueous $\mathrm{NaHCO}_{3}$. The organic phase was dried over $\mathrm{Na}_{2} \mathrm{SO}_{4}$, filtered and concentrated in vacuo to afford $\mathbf{1 2 b}(16 \mathrm{mg}, 23 \%)$ as a colorless solid. $[\alpha]_{\mathrm{D}}{ }^{29}+100^{\circ}\left(\right.$ c $\left.0.72, \mathrm{CHCl}_{3}\right) ;{ }^{1} \mathrm{H}$ NMR $\left(400 \mathrm{MHz}, \mathrm{CD}_{3} \mathrm{OD}\right)$ $\delta 5.26(\mathrm{~d}, J=5.6 \mathrm{~Hz}, 1 \mathrm{H}), 4.39(\mathrm{t}, J=7.8 \mathrm{~Hz}, 1 \mathrm{H}), 4.34(\mathrm{t}, J=7.8 \mathrm{~Hz}, 1 \mathrm{H}), 4.29$ (dd, $J=2.6,9.6 \mathrm{~Hz}, 1 \mathrm{H}), 4.16(\mathrm{~d}, J=9.6 \mathrm{~Hz}, 1 \mathrm{H}), 4.09(\mathrm{dd}, J=5.6,10.4 \mathrm{~Hz}$, $1 \mathrm{H}), 3.80-3.90(\mathrm{~m}, 3 \mathrm{H}), 3.70(\mathrm{~d}, J=3.2 \mathrm{~Hz}, 1 \mathrm{H}), 3.56(\mathrm{dd}, J=3.2,10.4 \mathrm{~Hz}$, $1 \mathrm{H}), 3.46(\mathrm{dq}, J=2.6,7.1 \mathrm{~Hz}, 1 \mathrm{H}), 3.22-3.30(\mathrm{~m}, 5 \mathrm{H}), 2.99(\mathrm{dd}, J=4.6$, $10.7 \mathrm{~Hz}, 1 \mathrm{H}), 2.42(\mathrm{~s}, 3 \mathrm{H}), 2.19(\mathrm{~s}, 3 \mathrm{H}), 2.05-2.17(\mathrm{~m}, 2 \mathrm{H}), 1.95-2.03(\mathrm{~m}, 1 \mathrm{H})$, $1.85(\mathrm{td}, J=10.2,12.8 \mathrm{~Hz}, 1 \mathrm{H}), 1.59-1.66(\mathrm{~m}, 2 \mathrm{H}), 1.49-1.57(\mathrm{~m}, 4 \mathrm{H})$, $1.31-1.38(\mathrm{~m}, 4 \mathrm{H}), 1.29(\mathrm{~d}, J=7.1 \mathrm{~Hz}, 3 \mathrm{H}), 0.90-0.94(\mathrm{~m}, 3 \mathrm{H}) ;{ }^{13} \mathrm{C}$ NMR $\left(125 \mathrm{MHz}, \mathrm{CD}_{3} \mathrm{OD}\right) \delta 178.0,164.0,90.5,72.0,71.3,70.4,69.9,69.5,63.9,61.3$, $60.1,54.3,46.9,42.9,42.3,39.2,38.7,37.0,33.2,27.0,25.5,22.6,21.0,14.6$, 14.5; MS (EI) $\mathrm{m} / z 588 \mathrm{M}^{+}$; HRMS (FAB) $\mathrm{m} / \mathrm{z}$ calcd for $\mathrm{C}_{27} \mathrm{H}_{49} \mathrm{~N}_{4} \mathrm{O}_{6} \mathrm{~S}_{2}$ 589.3094, found $589.3096(\mathrm{M}+\mathrm{H})^{+}$.

\section{In vitro antibacterial activity}

MIC was determined by the agar dilution method. Test strains were subjected to seed culture using sensitivity test broth (Nissui Pharmaceutical, Tokyo, Japan) cultured on blood agar plate for S. pneumoniae, S. pyogenes and $H$. influenzae. A 5- $\mu$ l portion of cell suspension of the test strains having about $10^{6} \mathrm{CFU}$ per $\mathrm{ml}$ was inoculated into sensitivity disk agar (Nissui Pharmaceutical) supplemented with $5 \%$ horse blood and incubated at $37^{\circ} \mathrm{C}$ for $20 \mathrm{~h}$. Then, MIC was defined as the lowest drug concentration that prevented visible growth.

\section{CONFLICT OF INTEREST}

The authors declare no conflict of interest.

\section{ACKNOWLEDGEMENTS}

We thank Mr A Tamura and Dr T Okutomi for valuable scientific discussion. We are grateful to Professor Emeritus Dr M Konno for supervision through our in-house drug discovery program in lincomycin field. We are also grateful to Ms T Miyara, Ms S Miki, Ms K Kaneda, Dr T Murata and Mr S Sato for contribution toward analytical chemistry, Mr T Matsuhira for biological studies, and Ms M Takagi for manuscript.

1 Weisblum, B. Erythromycin resistance by ribosome modification. Antimicrob. Agents Chemother. 39, 577-585 (1995).

2 Ajito, K., Miura, T., Furuuchi, T. \& Tamura, A. Sixteen-membered macrolides: chemical modifications and future applications. Heterocycles 89, 281-352 (2014).

3 Schlünzen, F. et al. Structural basis for the interaction of antibiotics with the peptidy transferase centre in eubacteria. Nature 413, 814-821 (2001)

4 Bannister, B. Modifications of lincomycin involving the carbohydrate portion. Part I. The 2-O-methyl and 2-deoxy-analogues. J. Chem. Soc. Perkin I 23, 3025-3030 (1972).

5 Sztaricskai, F. et al. Semisynthetic modification of antibiotic lincomycin. J. Antibiot. 49, 941-943 (1996)

6 Goffic, L. F. Structure activity relationships in lincosamide and streptogramin antibiotics. J. Antimicrob. Chemother. 16 (Suppl A), 13-21 (1985).

7 Umemura, E. et al. Synthesis of novel lincomycin derivatives and their in vitro antibacterial activities. J. Antibiot. 66, 195-198 (2013)

8 Isoda, T. et al. Syntheses and pharmacokinetic studies of prodrug esters for the development of oral carbapenem, L-084. J. Antibiot. 4, 241-247 (2006)

9 Remy, M. J., Tow-Keoght, A. C., MacConnell, S. T., Dalton, M. J. \& DeVito, A. J. Activity of delafloxacin against methicillin-resistant Staphylococcus aureus: resistance selection and characterization. J. Antimicrob. Chemother. 67, 2814-2820 (2012).

10 Igarashi, K. Chemical modification of tobramycin. Jpn J. Antibiot. 17 (Suppl), S187-S194 (1979).

11 Berkov-Zrihen, Y. et al. Synthesis and evaluation of hetero- and homodimers of ribosome-targeting antibiotics: antimicrobial activity, in vitro inhibition of translation, and drug resistance. J. Med. Chem. 56, 5613-5625 (2013)

12 Bannister, B. The S-Alkylation of sulphides by an activated carbohydrate epimine under acidic catalysis: the formation of $\alpha$-acetamido-sulphides. Part 4. Reactions with dithioacetals and monothioacetals. J. Chem. Soc. Perkin / 1980, 540-552 (1980).

13 Houtman, R. L. \& Mich, P. (The Upjohn Company), Trimethylsilyl ethers of lincomycin and its compounds. US3418414 (1966).

Supplementary Information accompanies the paper on The Journal of Antibiotics website (http://www.nature.com/ja) 